\title{
Laporan Kasus : Metode Kombinasi Modifikasi Ligasi Rubber Band dan Injeksi Sklerotik pada Hemoroid Derajat 1 dengan Menggunakan Paran Injection Ligation for Ambeien Pack (PILA Pack)
}

\author{
Case Report: Modification of Combination Method Rubber Band Ligation and Sclerotic Injection \\ on The First Degree of Hemorrhoids Used Paran Injection Ligation for Ambeien Pack (PILA Pack) \\ Fadli Robby Amsriza ${ }^{1}$, Rizka Fakhriani ${ }^{2 *}$ \\ ${ }^{1}$ Bagian Ilmu Bedah, Fakultas Kedokteran dan Ilmu Kesehatan Universitas Muhammadiyah Yogyakarta \\ ${ }^{2}$ Bagian Ilmu Kesehatan Telinga Hidung Tenggorok, Fakultas Kedokteran dan Ilmu Kesehatan Universitas \\ Muhammadiyah Yogyakarta
}

*Penulis korespondensi. Rizka Fakhriani. Email: rizkafakhriani@gmail.com

\begin{abstract}
ABSTRAK
Pendahuluan: Hemoroid merupakan penyakit pada regio anorektal yang umum terjadi dan dapat menyerang segala usia. Hemoroid terjadi akibat adanya pelebaran pembuluh darah pada bagian terbawah rektum dan anus. Hemoroid mempunyai gejala adanya perdarahan serta penonjolan pada anus. Diagnosis dan tatalaksana hemoroid yang tepat sangat penting untuk mengurangi morbiditas dan meningkatkan kualitas hidup pasien. Laporan kasus ini bertujuan untuk menyajikan kasus tatalaksana hemoroid derajat 1.

Laporan kasus: Pasien laki-laki, berusia 35 tahun, datang ke poliklinik bedah dengan keluhan perdarahan dari anus sejak 4 bulan yang lalu yang memberat 3 minggu terakhir. Perdarahan dari anus menetes berwarna merah segar terutama setelah buang air besar yang keras. Keluhan tidak disertai nyeri. Pada pemeriksaan fisik rectal toucher didapatkan tonus muskulospincter ani dalam batas normal, mukosa licin, ampula tidak kolaps, tidak teraba massa. Pada pemeriksaan anuskopi didapatkan lesi mukosa berwarna kebiruan pada arah jam 2. Berdasarkan anamnesis, pemeriksaan fisik, dan anuskopi, pasien didiagnosis dengan hemoroid interna derajat 1. Tatalaksana yang dilakukan adalah metode kombinasi modifikasi ligasi rubber band dan injeksi sklerotik dengan menggunakan Paran Injection Ligation for Ambeien Pack (PILA Pack). Pasien kontrol tujuh hari setelahnya dan pemeriksaan regio anorektal dalam batas normal. Kesimpulan: Diagnosis dan pemilihan terapi yang tepat sangat penting dalam penangan pasien hemoroid. Metode kombinasi ligasi rubber band dan injeksi sklerotik dapat menjadi salah satu pilihan terapi yang cukup efektif dalam tatalaksana hemoroid.
\end{abstract}

Kata kunci: hemorrhoid, ambeien, wasir, PILA, Paran Injection Ligation for Ambeien

\begin{abstract}
Introduction: Hemorrhoid is a common diseases in the anorectic region and can affect any age. Hemorrhoid occurs due to dilation of blood vessels at the lower of the rectum and anus. Hemorrhoid has symptoms of bleeding and protrusion of the anus. Diagnosis and proper management of hemorrhoids is important to increase the morbidity and the quality of life of patients. This case report aims to present a case of grade 1 hemorrhoid management.

Case report: Male patient, 35 years old, came to the surgical polyclinic with anal bleeding since 4 months ago which was getting heavier for the last 3 weeks. The bleeding was fresh red dripping especially after a hard bowel movement. The complaint was not accompanied by any pain. On physical examination of the rectal toucher, the muscle tone of the anal spincter was within normal limits, the mucosa was smooth, the ampulla did not collapse, and there was no mass palpable. On anuscopic examination, a bluish mucosal lesion was found at 2 o'clock. Based on the history, physical examination, and anuscopy, the patient was diagnosed with grade 1 internal hemorrhoids.The treatment was a combination technique of rubber band ligation and sclerotic injection using the Paran Injection Ligation for Hemorrhoid Pack. (PILA Pack). The patient was controled seven days later and the examination was within normal limits. Conclusion: Diagnosis and selection of the right therapy are highly important in the management of hemorrhoid patients. The combined method of rubber band ligation and sclerotic injection could be an effective therapeutic option in the management of hemorrhoids.
\end{abstract}

Key Words: hemorrhoid, PILA, Paran Injection Ligation for Ambeien 


\section{PENDAHULUAN}

Hemoroid merupakan penyakit yang paling umum pada regio anorektal. ${ }^{1,2,3}$ Patofisiologi secara pasti terjadinya hemoroid tidak diketahui. Hemoroid dapat terjadi di proximal atau distal dari linea dentata yang merupakan tempat transisi epitel columnar pada bagian proximal dengan bagian distal yaitu epitel skuamosa. Panjang anus adalah sekitar $4 \mathrm{~cm}$ pada dewasa, dengan linea dentata terletak pada bagian tengahnya. Hemoroid interna adalah hemoroid yang berkembang di atas linea dentata. Hemoroid interna tidak terasa nyeri karena dipersarafi secara visceral. Hemoroid eksterna berkembang di bawah linea dentata dan terasa nyeri jika membesar. Perluasan prolapse dari hemoroid interna dapat terbagi menjadi derajat satu sampai empat. ${ }^{4}$

Hemoroid merupakan suatu penyakit pada daerah anus yang paling sering diderita dengan prevalensi tertinggi pada semua kelompok umur. Sebuah laporan menyebutkan bahwa di Amerika Serikat terdapat 10 juta kasus hemoroid, yang mana presentasenya adalah $4,4 \%$ orang dari total penduduk. ${ }^{5}$ Penyakit tersebut terjadi karena beberapa faktor, antara lain; kurangnya konsumsi makanan berserat, konstipasi, usia, keturunan, kebiasaan duduk terlalu lama, peningkatan tekanan abdominal karena tumor, pola buang air besar yang salah, hubungan seks peranal, kurangnya asupan cairan, kurang olah raga dan kehamilan.

Hemoroid merupakan suatu kondisi anorektal yang tidak normal dengan gejala umum adanya perdarahan dari anus. Perubahan regio anorektal pada hemoroid antara lain dilatasi vena yang tidak normal, trombosis vaskuler, proses degeneratif pada serabut kolagen dan jaringan fibroelastik, distorsi dan pecahnya otot subepitel anus. Terdapat empat konsep dasar dari terjadinya hemoroid. Konsep yang pertama yaitu Sliding Anal Cushions. Konsep ini menyatakan bahwa sliding abnormal bantalan anus melalui lubang anus sebagai peristiwa patofisiologis yang umum sekali terjadi. Konsep inilah yang sering kali diterima oleh khalayak umum. Konsep yang kedua adalah Vascular Abnormality. Konsep ini menekankan bahwa terjadi aliran darah yang tidak normal dan menyebabkan terjadinya penumpukan sel-sel darah di bagian sekitar anus. Adanya abnormalitas vaskular dapat menyebabkan terjadinya hemoroid. Konsep berikutnya yaitu Rectal Redundancy dimana menyebutkan bahwa adanya rektum berlebih di bagian anus sehingga menyebabkan terjadinya pendarahan. Konsep terakhir adalah peningkatan tekanan Anorectal Vascular Plexus. Apabila terjadi penekanan yang tidak wajar atau berlebihan, maka akan terdapat benjolan yang keluar dari saluran anus dan inilah yang disebut dengan hemoroid. ${ }^{6}$

Penjelasan di atas memberikan sebuah fenomena bahwa hemoroid merupakan suatu penyakit yang memerlukan tatalaksana yang tepat dan efektif. Salah satu pilihan tatalaksana hemoroid adalah dengan ligasi rubber band. ${ }^{7}$ Ligasi rubber band juga merupakan tindakan non-invasif yang efektif untuk menghilangkan gejala hemoroid internal. Ligasi rubber band memiliki keunggulan meminimaliris rasa nyeri, hemat biaya, dan sangat berguna pada hemoroid internal stadium dini. ${ }^{8}$ Laporan kasus bertujuan untuk menyajikan kasus seorang pasien dengan hemoroid derajat I yang mendapaatkan terapi kombinasi modifikasi ligasi rubber band dan injeksi sklerotik dengan menggunakan Paran Injection Ligation for Ambeien Pack (PILA Pack)

\section{LAPORAN KASUS}

Seorang laki-laki berusia 35 tahun datang ke poliklinik bedah dengan keluhan perdarahan dari anus sejak 4 bulan yang lalu yang memberat 3 minggu terakhir. Perdarahan dari anus menetes berwarna merah segar terutama saat buang air besar keras. Keluhan tidak disertai nyeri. Pada pemeriksaan fisik rectal toucher didapatkan tonus muskulo spincter ani dalam batas normal, mukosa licin, ampula tidak kolaps, tidak teraba massa. Pada pemeriksaan 
anuskopi didapatkan lesi mukosa berwarna kebiruan pada arah jam 2 (gambar 1.). Berdasarkan anamnesis, pemeriksaan fisik, dan anuskopi, pasien didiagnosis dengan hemoroid interna derajat 1 . Pasien tersebut sudah melakukan perubahan pola diet dengan tinggi serat akan tetapi belum menunjukkan adanya perbaikan. Pasien tersebut dilakukan tatalaksana dengan metode kombinasi modifikasi ligasi rubber band dan injeksi sklerotik dengan menggunakan Paran Injection Ligation for Ambeien Pack (PILA pack). Pemeriksaan anuskopi setelah dilakukan tindakan terlampir dalam gambar 2 . Pasien kontrol ke poliklinik bedah 1 minggu setelahnya, keluhan nyeri dan perdarahan dari anus tidak ada. Pada pemeriksaan fisik rectal toucher didapatkan tonus muskulo spincter ani dalam batas normal, mukosa licin, ampula tidak kolaps, dan tidak teraba massa.

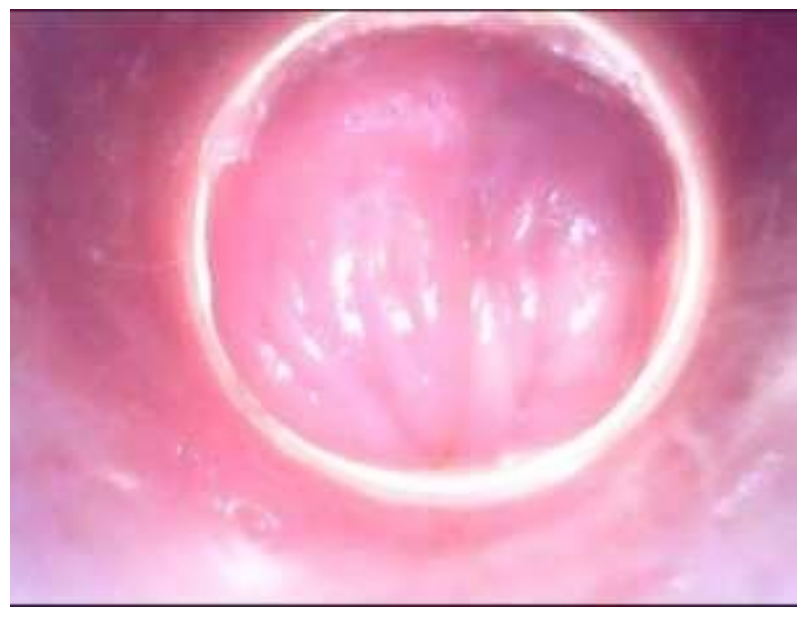

Gambar 1. Hasil pemeriksaan anuskopi sebelum tindakan

(Dokumentasi pribadi Fadli Robby Amsriza)

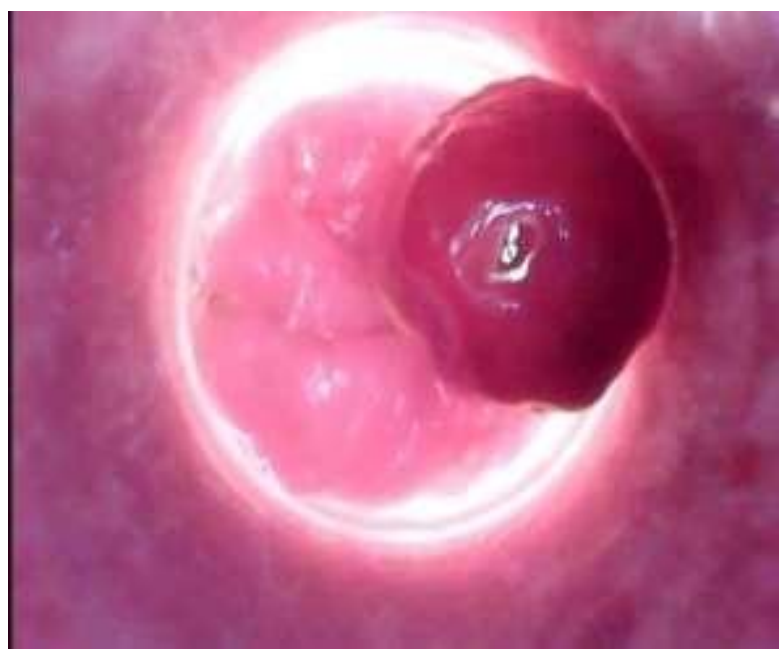

Gambar 2. Hasil pemeriksaan anuskopi setelah tindakan

(Dokumentasi pribadi Fadli Robby Amsriza) 


\section{DISKUSI}

Hemoroid merupakan penyakit pada daerah anorektal yang umum terjadi pada populasi dewasa di seluruh dunia dan berhubungan dengan masalah medis utama serta sosial ekonomi. ${ }^{9}$ Eksaserbasi dari penyakit ini dapat berpengaruh signifikan terhadap kualitas hidup pasien. Sekitar 20\% pasien akan membutuhkan terapi bedah dan rehabilitasi yang selanjutnya dapat meningkatkan waktu penyembuhan dan kehilangan hari kerja. ${ }^{3,9}$

Gejala utama dari hemoroid adalah perdarahan, nyeri, prolaps, bengkak dan gatal pada anus, serta adanya feses berlendir. Gejala hemoroid tergantung pada kondisi tertentu seperti ukuran, dan jenis hemoroid, apakah hemoroid interna atau eksterna, dan apakah penyakitnya akut atau kronis. Dalam beberapa kasus mungkin ada terdapat satu gejala, tetapi beberapa gejala mungkin dapat muncul bersama. ${ }^{10}$ Pada kasus ini, pasien merupakan laki-laki berusia 35 tahun dengan keluhan utama adanya perdarahan dari anus tanpa adanya gejala nyeri dan prolapse dari anus. Anamnesis pasien tersebut menunjukkan adanya kemungkinan adanya hemoroid interna, dimana gejala hemoroid interna pada umumnya adalah perdarahan dari anus tanpa adanya nyeri. Empat dari 10 pasien dengan hemoroid adalah asimtomatik. Belum diketahui secara pasti mengapa hemoroid menjadi simtomatik. Beberapa literatur menjelaskan bahwa hemoroid menjadi bergejala jika terjadi proses pergeseran bantalan anus. ${ }^{3}$ Perdarahan pada anus merupakan gejala yang paling umum pada hemoroid interna. ${ }^{11}$ Adanya perdarahan anus tanpa adanya rasa nyeri disebabkan karena tidak adanya serabut saraf nyeri. ${ }^{12}$

Perdarahan anus pada hemoroid disebabkan karena kongesti dari sinusoid, berpindah ke belakang ke arteriol presinusoidal. Oleh karena itu, perdarahan dari hemoroid berasal dari arteri, sehingga berwarna merah segar. $^{13,14}$

Pemeriksaan fisik yang diperlukan pada kasus hemoroid adalah inspeksi pada area perineal dan rektum. Posisi pasien dapat lateral decubitus, lithotomy, atau posisi prone jackknife. ${ }^{4}$ Pada inspeksi dapat dijumpai adanya hemoroid eksterna atau prolaps dari hemoroid interna. Pada pemeriksaan rectal toucher dapat mengetahui adanya massa, nyeri tekan, dan adanya fluktuasi. Akan tetapi, hemoroid interna jarang teraba kecuali jika membesar dan prolapse. ${ }^{4}$ Hal tersebut sesuai dengan pasien pada kasus ini, dimana didapatkan tonus muskulospincter ani dalam batas normal, mukosa licin, ampula tidak kolaps, dan tidak teraba massa.

Pasien pada kasus ini dilakukan pemeriksaan anoskopi. Pedoman dari sebagian besar komunitas gastrointestinal dan bedah menyarankan pemeriksaan anoskopi dan/atau sigmoidoskopi fleksibel untuk mengevaluasi adanya perdarahan dari rektum yang berwarna merah cerah. The American Society of Colon and Rectal Surgeons (ASCRS) merekomendasikan evaluasi endoskopik kolon lengkap pada pasien dengan hemoroid bergejala dan perdarahan rektal. ${ }^{10,15}$ Anuskopi merupakan pemeriksaan yang efektif untuk mengamati hemoroid interna yang akan terlihat seperti tonjolan berwarna keunguan. ${ }^{4}$ Hal tersebut sesuai dengan kasus pada pasien ini, dimana pada pemeriksaan anuskopi didapatkan lesi mukosa berwarna kebiruan pada arah jam 2.

Berdasarkan anamnesis dan pemeriksaan fisik pasien pada kasus ini didiagnosis dengan hemoroid interna derajat 1 . Hemoroid interna terdiri dari 4 derajat. Hemoroid derajat 1 ditandai dengan adanya perkembangan mukosa rektum asimtomatik yang disebabkan oleh pembengkakan pleksus hemoroidalis dan kelemahan dinding rektum. Hemoroid derajat 2 ditandai dengan adanya prolaps saat buang air besar atau saat megejan dimana prolaps tersebut dapat tereduksi secara spontan. Hemoroid derajat 3 ditandai dengan adanya prolaps yang membutuhkan reduksi manual. Derajat terakhir ditandai dengan adanya prolaps yang tidak dapat direduksi dan sering disertai perubahan inflamasi lokal kronis." Dalam hasil laporan kasus ini, pasien mengalami hemoroid derajat 1 karena adanya 
perdarahan dari anus dengan adanya lesi mukosa berwarna kebiruan pada arah jam 2 pada anuskopi.

Pedoman tatalaksana hemoroid tercantum dari American Gastroenterological Association (AGA), ${ }^{11}$ the American Society of Colon and Rectal Surgeons (ASCRS), the American College of Gastroenterology $(A C G){ }^{16}$ dan the American Academy of Family Physicians. ${ }^{4}$ Pedoman dari ACG dan ASCSR, merekomendasikan pasien hemoroid simtomatik dengan diet tinggi serat dan asupan cairan yang cukup serta konseling kebiasaan buang air besar. ${ }^{15,16}$ Pengobatan konservatif lini pertama hemoroid terdiri dari diet tinggi serat (25 hingga 35 gram per hari), suplememtasi serat, penungkatan asupan air, dan pemberian pelunak feses. ${ }^{4}$ Pedoman ACG juga merekomendasikan bahwa jika modifikasi pola makan tidak akan menghilangkan gejala pada pasien dengan hemoroid derajat 1 sampai 3, perlu dipertimbangkan beberapa prosedur seperti banding, skleroterapi, koagulasi infrared, serta ligasi. ACG juga merekomendasikan bahwa pasien harus dirujuk untuk operasi jika refrakter, atau tidak dapat mentolelir prosedur tersebut, atau jika hemoroid disertai dengan gejala berat, hemoroid derajat 4, serta hemoroid derajat 3 besar, ${ }^{16}$ ASCRS menyatakan bahwa prosedur banding, skleroterapi, koagulasi inframerah dapat efektif untuk sebagian besar kasus hemoroid derajat I dan II dan kasus tertentu hemoroid internal derajat III refrakter. ${ }^{15}$ Prosedur banding dilakukan dengan memasukkan instrumen ligase melalui anuskop untuk menyedot target hemorid kemudian rubber band di ikatkan pada pedikel hemoroid tersebut sehingga terjadi nekrosis iskemik. ${ }^{4}$ Skleroterapi merupakan suatu metode penyuntukan agen sclerosis secara submucosa ke dasar hemoroid yang dapat menginduksi reaksi inflamasi yang kemudian dapat memperkecil massa hemoroid. ${ }^{24}$ Koagulasi inframerah dapat menstimulasi nekrosis pada dasar proksimal hemoroid. ${ }^{4}$ Dokter dapat menawarkan prosedur bedah dengan tindakan hemoroidektomi kepada pasien dengan hemoroid eksterna simptomatik atau gabungan hemoroid internal/ eksternal dengan prolaps. ${ }^{15}$

AFP (American Family Physician) merekomendasikan peningkatan asupan serat sebagai pengobatan lini pertama yang efektif dan non-bedah. ${ }^{4} \quad$ Pengobatan hemoroid derajat I-III seperti ligasi rubber band lebih disukai, sedangkan hemoroidektomi eksisi (konvensional) efektif untuk hemoroid derajat IV, berulang, atau sangat bergejala. ${ }^{4}$

Pasien pada kasus ini dilakukan tatalaksana dengan metode kombinasi modifikasi ligasi rubber band dan injeksi sklerotik dengan menggunakan Paran Injection Ligation for Ambeien pack (PILA pack). Prinsip teknik ligasi rubber band adalah mengikat mukosa dan submucosa pada bantalan anus. Pengikatan tersebut menimbulkan peradangan, dengan iskemia dan nekrosis nekrosis pada bagian yang terikat. Selain menghilangkan nodul, sekuel terakhir dari prosedur ini adalah fibrosis yang dihasilkan, memperbaiki jaringan yang tersisa di jaringan di bawah saluran anus dan mengoreksi prolaps. ${ }^{11,12,17,18}$ Terapi ini dianggap sebagai terapi andalan untuk hemoroid derajat I dan II dan pasien terpilih dengan derajat III. ${ }^{14,19,20} \quad$ Beberapa penelitian telah membuktikan bahwa prosedur terapeutik invasif minimal ini efisien, dapat diandalkan dan aman untuk pasien hemoroid. ${ }^{20,21}$

PILA Pack merupakan suatu alat yang digunakan pada metode kombinasi modifikasi ligasi rubber band dan injeksi sklerotik. PILA Pack merupakan suatu alat disposable yang terdiri dari 1 buah ligator, 1 buah anuskop, dan 1 buah o ring atau silicon rubber (gambar 3.). PILA Pack diproduksi dalam negeri dan telah mendapatkan ijin edar dari Kementrian Kesehatan Republik Indonesia. Adapun tatacara penggunaaan PILA pack adalah posisikan pasien dengan posis bersujud kemudian lumuri anus dengan pelumas dan masukkan anoskop untuk menetukan posisi dan ukuran hemoroid. Prosedur dilanjutkan dengan penyuntikan hemoroid dengan agen sklerotik yaitu polidocanol 3\% kemudian masukkan suction 
ligator dengan ujung diarahkan ke massa hemoroid yang telah disuntik. Prosedur dilanjutkan dengan melakukan penghisapan hemoroid dengan alat suction hingga hemoroid terhisap ke dalam suction ligator sampai pangkalnya. Hemoroid harus terhisap dengan tepat kemudianorong silicon rubber atau $o$ ring yang berada di ujung suction ligator dengan pemantik yang ada di suction ligator. Jika sudah terikat, maka lakukan penyuntikan kembali dengan agen sklerotik, kemudian keluarkan anoskop dari lubang anus. Hemoroid yang telah di suntik dan diikat akan terlepas dengan sendirinya pada hari ke 4-7 setelah tindakan.

Perbedaan metode kombinasi modifikasi ligasi rubber band dan injeksi sklerotik menggunakan Paran Injection Ligation for Ambeien pack (PILA pack) dengan metode kombinasi ligasi rubber band dan injeksi sklerotik terletak pada teknik injeksi. Frekuensi injeksi pada metode kombinasi modifikasi ligase rubber band dan injeksi sklerotik dilakukan sebanyak dua kali yaitu sebelum masukkan suction ligator ke massa hemoroid dan setelah pengikatan dengan silicon rubber.

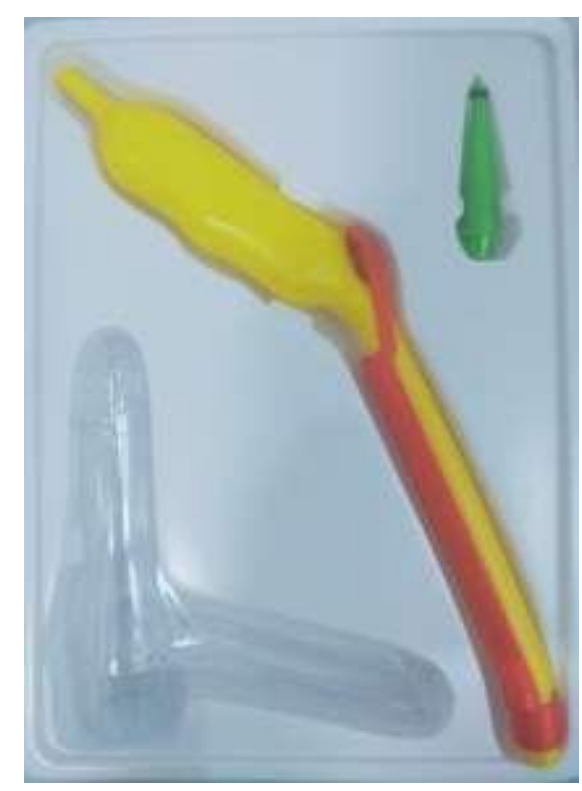

Gambar 3. PILA Pack yang terdiri dari 1. Anuskop; 2. ligator; 3. O ring silicon rubber dan aplikator ( Dokumentasi pribadi Fadli Robby Amsriza)

Ligasi rubber band telah dianggap sebagai salah satu tatalaksana yang cukup efektif untuk hemoroid. Masalah yang cukup mengganggu dari tindakan tersebut adalah rasa nyeri pasca ligasi dan ketidaknyamanan terkait ligasi rubber band. Tindakan lain yang dapat dilakukan pada hemoroid adalah injeksi skleroterapi yang relatif mudah dan banyak digunakan. Beberapa penelitan menunjukkan bahwa metode kombinasi ligasi rubber band dan injeksi skleroterapi cukup efektif. $^{22}$ Sebuah penelitian pada Thai Journal of Surgery menunjukkan bahwa kombinasi ligasi rubber band dengan injeksi sklerotik lebih efektif dibandingkan dengan ligasi rubber band saja. Tindakan pada pasien di kasus ini cukup berhasil. Pasien control kembali ke poliklinik bedah 1 minggu setelah tindakan, keluhan nyeri dan perdarahan dari anus tidak ada. ${ }^{23}$

\section{KESIMPULAN DAN SARAN}


Telah dilaporkan pasien laki-laki usia berusia 35 tahun dengan diagnosis hemoroid interna derajat 1. Pada pasien ini telah dilakukan tindakan dengan teknik kombinasi modifikasi ligasi rubber band dan injeksi sklerotik dengan menggunakan Paran Injection Ligation for Ambeien pack (PILA Pack). Setelah dilakukan tindakan, keluhan nyeri dan perdarahan dari anus tidak ada.

\section{DAFTAR PUSTAKA}

1. Nikam V, Deshpande A, Chandorkar I, Sahoo S. A prospective study of efficacy and safety of ligasi rubber band in the treatment of Grade II and III hemorrhoids - a western Indian experience. Journal of Coloproctology. 2018;38(3): 189-193.

2. Suprijono MA. Hemorrhoid. Majalah Ilmiah Sultan Agung. 2018;44(118): 2338.

3. Zagriadskiı̌ EA, Bogomazov AM, Golovko EB. Conservative treatment of hemorrhoids: results of an observational multicenter study. Advances in therapy. 2018;35(11):1979-1992.

4. Mott T, Latimer K, Edwards C. Hemorrhoids: diagnosis and treatment options. American family physician. 2018;97(3): 172-179.

5. Mukherjee R, Shenoy P, Saha S, Mukhopadhyay G. A prospective evaluation of ligasi rubber band, sclerotherapy and combined method of these two procedures in management of haemorrhoids:an interim result analysis. International Journal of Scientific Research. 2017; 6(11): 196-199.

6. Margetis N. Pathophysiology of internal hemorrhoids. Annals of gastroenterology. 2019;32(3): 264-272.

7. Shweta V, Akhlesh B. Role of ligasi rubber band as a non-invasive treatment in haemorrhoid wsr to internal haemorrhoids. International Journal of Ayurveda and Pharma Research. 2020;8(10): 79-83.

8. Gardner IH, Siddharthan RV, Tsikitis VL. Benign anorectal disease: hemorrhoids, fissures, and fistulas. Annals of gastroenterology. 2020;33(1): 9-18.

9. Song SG, Kim SH. Optimal treatment of symptomatic hemorrhoids. Journal of the Korean Society of Coloproctology. 2011;27(6): 277-281.

10. Yamana T. Japanese practice guidelines for anal disorders I. hemorrhoids. Journal of the anus, rectum and colon. 2017;1(3): 89-99.

11. Madoff RD, Fleshman JW. American gastroenterological association technical review on the diagnosis and treatment of hemorrhoids. Gastroenterology. 2004;126(5): 1463-1473.

12. Sun Z, Migaly J. Review of hemorrhoid disease: presentation and management. Clinics in colon and rectal surgery. 2016;29(1): 22-29.

13. Bernstein WC. What are hemorrhoids and what is their relationship to the portal venous system?. Diseases of the Colon \& Rectum. 1983; 26(12): 829-834.

14. Ganz RA. The evaluation and treatment of hemorrhoids: a guide for the gastroenterologist. Clinical Gastroenterol and Hepatol. 2013;11(6): 593-603.

15. Davis BR, Lee-Kong SA, Migaly J, Feingold DL, Steele SR. The American Society of Colon and Rectal Surgeons Clinical Practice Guidelines for the Management of Hemorrhoids. Dis Colon Rectum. 2018 Mar;61(3): 284-292.

16. Wald A, Bharucha AE, Cosman BC, William EW. ACG clinical guideline: management of benign anorectal disorders. Am J Gastroenterol. 2014 Aug;109(8): 1141-1157.

17. Lestar B, Penninckx F, Kerremans R. The composition of anal basal pressure. An in vivo and in vitro study in man. Int $J$ Colorectal Dis. 1989;4(2): 118-122.

18. Iyer VS, Shrier I, Gordon PH. Long-term outcome of ligasi rubber band for symptomatic primary and recurrent internal hemorrhoids. Dis Colon Rectum. 2004;47(8): 1364-1370.

19. Hall JF. Modern management of 
hemorrhoidal disease. Gastroenterol Clin North Am. 2013;42(4): 759-772

20. Khan AN, Khan NA. A prospective study of outcome from ligasi rubber band in third degree haemorrhoids. J Pak Med Assoc. 2010;60(11): 952-955.

21. Cocorullo G, Tutino R, Falco N, Licari L, Orlando G, Fontana T, et al. The nonsurgical management for hemorrhoidal disease. A systematic review. $G$ Chir. 2017;38(1): 5-14.

22. Nasir MA, Masroor R, Arafat Y, Butt Q, Sarwar S. Injection sclerotherapy versus ligasi rubber band for second degree hemorrhoids. Pakistan Armed Forces Medical Journal. 2017;67(6): 996-1002.

23. Pattaropong K, Wanitsuwan W. Effectiveness of the treatment of internal hemorrhoid grade 2-3 with ligasi rubber band and sclerotherapy compare with ligasi rubber band alone. Thai Journal of Surgery. 2020. 41(4): 157

24. Awan SL, Abbasi MA, Shakil M, Ayub M. Comparison between injection sclerotherapy and rubber band ligation for first and second degree haemorrhoids. Pakistan Journal of Physiology. 2017;13(2): 15-18. 